\title{
Combination therapy for severe portopulmonary hypertension in a child allows for liver transplantation
}

\author{
Ryan M. Serrano ${ }^{1}$, Girish C. Subbarao ${ }^{2}$, Richard S. Mangus ${ }^{3}$, Greg Montgomery ${ }^{4}$, \\ Michael Johansen ${ }^{1}$.
}

1. Department of Pediatrics, Division of Pediatric Cardiology, Indiana University School of Medicine, Riley Hospital for Children at Indiana University Health, Indianapolis, Indiana.

2. Department of Pediatrics, Division of Gastroenterology, Hepatology, and Nutrition, University of Indiana School of Medicine and Riley Children's Hospital, Indianapolis, Indiana.

3. Department of Surgery, Transplant Division, Indiana University School of Medicine, Indianapolis, Indiana.

4. Section of Pediatric Pulmonology, Critical Care and Allergy, PICU/Riley Hospital for Children, Indianapolis, Indiana.

This is the author's manuscript of the article published in final edited form as:

Serrano, R. M., Subbarao, G. C., Mangus, R. S., Montgomery, G., \& Johansen, M. (2019). Combination therapy for severe portopulmonary hypertension in a child allows for liver transplantation. Pediatric Transplantation, 23(5), e13461. https://doi.org/10.1111/petr.13461 


\begin{abstract}
Severe PPHTN is a contraindication to liver transplantation and predicts an abysmal 5-year outcome. It is defined as a resting mPAP $>45 \mathrm{~mm} \mathrm{Hg}$ with a mean pulmonary artery wedge pressure of $<15 \mathrm{~mm} \mathrm{Hg}$ and pulmonary vascular resistance of $>3$ wood units in the setting of portal hypertension. There have been limited reports of successful treatment of PPHTN leading to successful liver transplantation in adults, and one reported use of monotherapy as a bridge to successful liver transplant in pediatrics. To our knowledge, we describe the first use of combination therapy as a successful bridge to liver transplantation in a pediatric patient with severe PPHTN. This report adds to the paucity of data in pediatrics on the use of pulmonary vasodilator therapy in patients with severe PPHTN as a bridge to successful liver transplantation. Early diagnosis in order to mitigate or avoid the development of irreversible pulmonary vasculopathy that would preclude candidacy for liver transplantation is crucial, but our report demonstrates that combination therapy can be administered safely, quickly, and may allow for successful liver transplantation in patients with severe PPHTN.
\end{abstract}

\title{
Abbreviations
}

6MW :6-minute walk

$\mathrm{ALT}$ : alanine transaminase

AST: aspartate aminotransferase

CPAP: continuous positive airway pressure

CT: computed tomography

ERA: endothelin receptor antagonist

FEV1: forced expiratory volume at one second

FVC: forced vital capacity

HIV: human immunodeficiency virus
iNO: inhaled nitric oxide

IVC: inferior vena cava

mPAP: mean pulmonary artery pressure

PA: pulmonary artery

PFT: pulmonary function test

PPHTN: portopulmonary hypertension

PVR: pulmonary vascular resistance

$\mathrm{RV}$ : right ventricle

TR: tricuspid regurgitation

Keywords: congenital hepatic fibrosis pediatric liver transplantation portopulmonary hypertension 


\section{INTRODUCTION}

PPHTN is a potentially fatal complication in patients with chronic liver disease, $\mathbf{1}$ defined as a resting $\mathrm{mPAP} \geq 25 \mathrm{~mm} \mathrm{Hg}$, a mean pulmonary artery wedge pressure of $\leq 15 \mathrm{~mm} \mathrm{Hg}$, and pulmonary vascular resistance $>3$ wood units in the setting of portal hypertension. The clinical symptoms are often insidious, making the initial diagnosis elusive. Prognosis varies depending on the severity of liver disease and response to pulmonary hypertension therapy and/or liver transplantation, and 5-year survival is reported between $14 \%$ and $40 \% . \underline{\mathbf{2}}-\underline{\mathbf{5}}$ Liver transplantation with reversal of portal hypertension offers the highest likelihood of survival. Unfortunately, those who develop severe PPHTN are often prospectively excluded from transplantation secondary to unacceptably high mortality rates.1

There have been successful reports of intravenous epoprostenol, sildenafil, or treprostinil allowing successful liver transplantation in adult patients with varying degrees of portopulmonary hypertension. $\underline{\mathbf{6}}-\underline{10} \mathrm{~A}$ single case report of successful use of epoprostenol in a pediatric patient exists, $\underline{11}$ and there are no reports of pediatric patients treated with early combination therapy for severe portopulmonary hypertension surviving to transplant. We report a 15-year-old female with idiopathic cirrhosis and severe PPHTN treated with treprostinil, tadalafil, and macitentan prior to successful orthotopic liver transplant and hospital discharge and whose medications were weaned and discontinued several months after transplant.

\section{CASE REPORT}

Our patient is a 15-year-old female with idiopathic cirrhosis diagnosed at 8 months of age. An echocardiogram performed at the time of diagnosis showed normal cardiac anatomy and function. Her course was complicated by portal hypertension as evidenced by multiple episodes of variceal rupture and need for variceal banding at the age of 5 years. She had spontaneous formation of a portal vein to IVC shunt noted in 2009.

Her medications included phytonadione $5 \mathrm{mg}$ twice daily, propranolol $30 \mathrm{mg}$ twice daily, coenzyme Q10 $200 \mathrm{mg}$ daily, zinc sulfate $110 \mathrm{mg}$ daily, and vitamin $\mathrm{A}, \mathrm{D}$, and $\mathrm{E}$ supplementation. She was doing well until she developed a persistent cough, which did 
not improve with a course of azithromycin. A chest X-ray showed a nodular mass-like appearance in the left hilum thought to be reflective of enlargement of the pulmonary artery (Figure 1). A CT of the chest showed markedly dilated central pulmonary vasculature consistent with pulmonary hypertension (Figure 2 ) and no evidence of filling defects. An echocardiogram showed normal left ventricular function, RV/PA systolic pressures of 75-85 mm Hg based on TR, pulmonary artery diastolic pressures between $30-40 \mathrm{~mm} \mathrm{Hg}$ based on pulmonary regurgitation, and a moderately hypertrophied right ventricle with mildly diminished systolic function. Right-sided hemodynamics were assessed by cardiac catheterization and confirmed severe pulmonary hypertension and increased pulmonary vascular resistance with mild response to iNO and oxygen (Table 1). She was admitted for initiation of pulmonary vasodilator therapy. Previous workup for her cirrhosis found no evidence of infectious hepatitis nor autoimmune hepatitis, making an autoimmune etiology for her pulmonary hypertension unlikely. Spirometry was suggestive of mild restrictive physiology with FVC of $60 \%$ predicted, FEV1 of $59 \%$ predicted, and an FEV1/FVC ratio of $88 \%$. A polysomnogram showed mild obstructive sleep apnea with an apnea hypopnea index of 3.9 per hour on room air and low mean oxygen saturations consistent with pulmonary vascular disease. Additional workup excluded infectious etiologies such as HIV, a hypercoagulable state or thromboembolic phenomena, pregnancy, and thyroid disease. A BNP on admission was $1977 \mathrm{pg} / \mathrm{mL}$, and 6MW distance was significantly diminished at $299 \mathrm{~m}$ while receiving $2 \mathrm{~L}$ oxygen by nasal cannula.

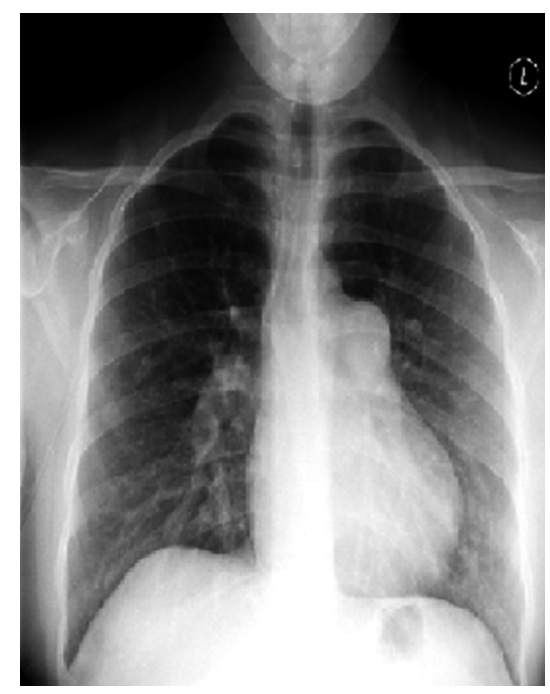




\section{Figure 1}

Chest X-ray showing mass-like area in the left hilar region representing aneurysmal change in the pulmonary artery secondary to pulmonary hypertension

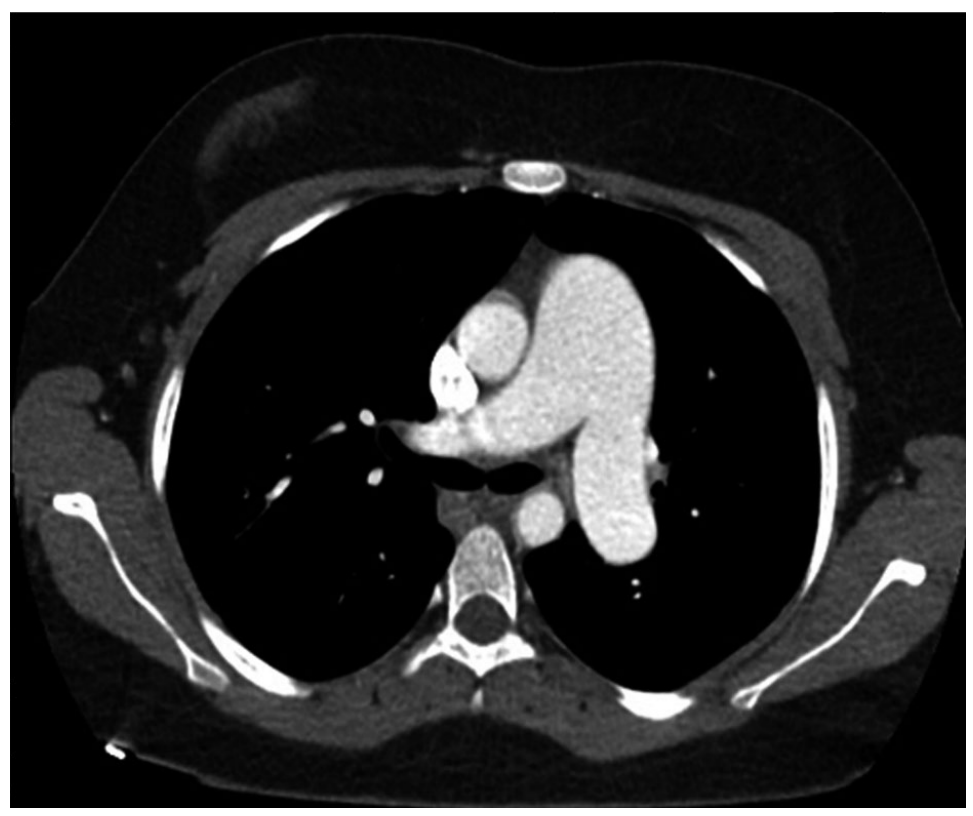

Figure 2.

CT scan showing a markedly dilated pulmonary artery measuring $4.2 \mathrm{~cm}$ in diameter. The left and right pulmonary arteries are also markedly dilated

Table 1. Right and left heart hemodynamics before and after pulmonary vasodilator therapy

$\begin{array}{lllll}\text { Measurements } & & \begin{array}{l}\text { Initial } \\ \text { diagnosis }\end{array} & \begin{array}{l}\text { Initial diagnosis-40 ppm } \\ \mathbf{1 0 0 \%} \text { FiO2 }\end{array} & \begin{array}{l}\text { NO, } \\ \text { Two months post- } \\ \text { treatment }\end{array} \\ \begin{array}{l}\text { Pulmonary } \\ \text { resistance }\end{array} & \text { vascular } & 16.75 & 13.78 & 2.38 \\ \text { PVR/SVR ratio } & 0.92 & 0.83 & 27 \\ \begin{array}{l}\text { Mean pulmonary } \\ \text { pressure }\end{array} & \text { artery } & 72 & 62 & \end{array}$




\begin{tabular}{|c|c|c|c|}
\hline Measurements & $\begin{array}{l}\text { Initial } \\
\text { diagnosis }\end{array}$ & $\begin{array}{l}\text { Initial diagnosis-40 ppm NO, } \\
100 \% \text { FiO2 }\end{array}$ & $\begin{array}{l}\text { Two months } \\
\text { treatment }\end{array}$ \\
\hline Capillary wedge pressure & 11 & 10 & 14 \\
\hline Transpulmonary gradient & 61 & 51 & 13 \\
\hline Cardiac Index & 3.64 & 3.77 & 5.89 \\
\hline Right ventricular pressure & $91 / 68$ & $79 / 11$ & $35 / 13$ \\
\hline Aorta blood pressure & $97 / 60$ & $84 / 60$ & $95 / 40 \underline{a}$ \\
\hline
\end{tabular}

- Units: pulmonary vascular resistance-woods units $\times \mathrm{m}^{2}$; all intracardiac pressures are expressed in $\mathrm{mm} \mathrm{Hg}$; cardiac index- $\mathrm{L} / \mathrm{min} / \mathrm{m}^{2}$.

- Abbreviations: FiO2, fraction of inspired oxygen; NO, nitric oxide; ppm, parts per million; PVR, pulmonary vascular resistance; SVR, systemic vascular resistance.

- a The aorta blood pressure done at 2 mo post-treatment is a non-invasive measurement.

She was initiated on milrinone at $0.3 \mathrm{mcg} / \mathrm{kg} / \mathrm{min}$, subcutaneous treprostinil at an infusion rate of $2.1 \mathrm{ng} / \mathrm{kg} / \mathrm{min}$, and tadalafil $40 \mathrm{mg}$ daily. Her treprostinil dose was initially quickly increased but had to be slowed secondary to side effects including headache, nausea, diarrhea, tachycardia, and systemic hypotension. The milrinone infusion was stopped, and she was started on low dose dopamine at $3 \mathrm{mcg} / \mathrm{kg} / \mathrm{min}$ as her treprostinil was increased. She was also started on furosemide and spironolactone, though furosemide was discontinued. She was discharged on treprostinil at $23.5 \mathrm{ng} / \mathrm{kg} / \mathrm{min}$ and tadalafil $40 \mathrm{mg}$ daily. ERA therapy was not started due to elevated serum alanine and aspartate aminotransferase levels of 82 and $108 \mathrm{mg} / \mathrm{dL}$, respectively, and a bilirubin level of $8.7 \mathrm{mg} / \mathrm{dL}$. Nocturnal CPAP at $6 \mathrm{~cm} \mathrm{H} \mathrm{H}_{2} \mathrm{O}$ with 2-3 $\mathrm{L}$ of oxygen was initiated, which markedly improved her cough. 
At follow-up 12 days after discharge, an echocardiogram showed significant improvement in right ventricular pressure (Figure $\underline{\mathbf{3}}$ ). Due to continued gastrointestinal side effects, treprostinil was decreased to $21.4 \mathrm{ng} / \mathrm{kg} / \mathrm{min}$. She had significant improvement in serum ALT and AST (31 and $41 \mathrm{mg} / \mathrm{dL}$, respectively) and a bilirubin level of $2.4 \mathrm{mg} / \mathrm{dL}$, so she was started on macitentan $5 \mathrm{mg}$ daily and increased to $10 \mathrm{mg}$ daily after two weeks. She underwent repeat cardiac catheterization approximately 2 months after starting pulmonary vasodilator therapy, which showed marked improvement in her hemodynamics (Table 1).

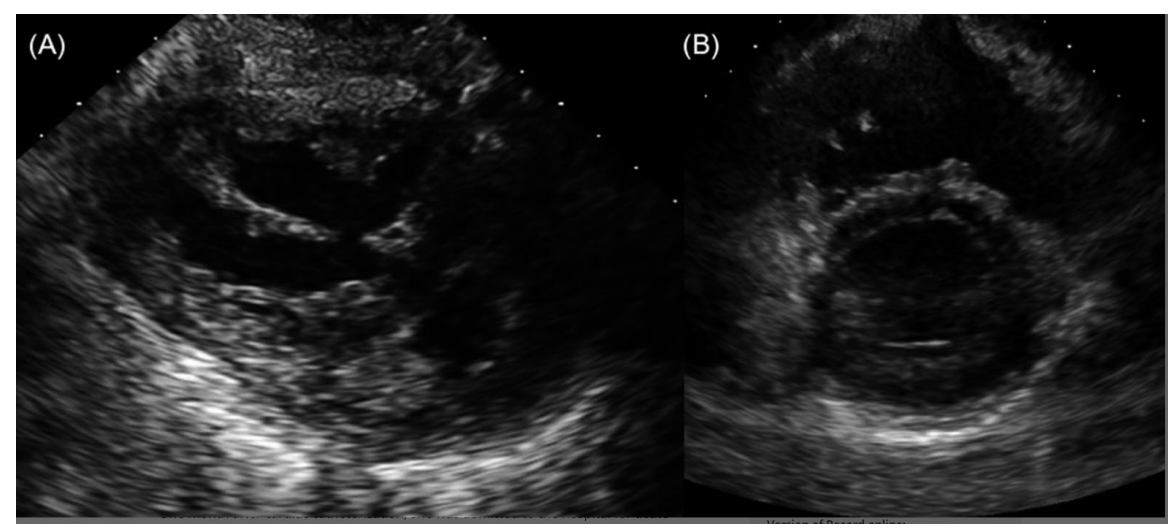

Figure 3.

Parasternal short-axis view (A) with flattening of the interventricular septum and a dilated, hypertrophied right ventricle. After initiation of pulmonary vasodilator therapy, there is significant improvement in the septal position and right ventricular size (B)

One month after cardiac catheterization, she was admitted to the hospital for acute cholecystitis. She was managed medically until a liver donor offer became available 7 days later. One day prior to liver transplantation, she was transitioned from subcutaneous to intravenous treprostinil therapy without incident. A Swan-Ganz catheter was placed in the operating room via the right internal jugular vein approach prior to initiation of the transplant surgery, demonstrating a mPAP of $32 \mathrm{~mm} \mathrm{Hg}$, right atrial pressure of $10 \mathrm{~mm} \mathrm{Hg}$, and pulmonary artery wedge pressure of $8 \mathrm{~mm} \mathrm{Hg}$. During the surgery, mean pressure rose to $15 \mathrm{~mm} \mathrm{Hg}$ in the right atrium and 37 in the pulmonary artery. Inhaled nitric oxide was initiated with no immediate effect. Thirty minutes later, the hemodynamics returned to baseline. In the immediate post-operative period, she spent 
6 days in the intensive care unit followed by 6 days on the cardiac step-down unit. Enteral phosphodiesterase inhibitor and ERA therapies were continued on post-operative day 2 as iNO was weaned off. Intravenous treprostinil was transitioned back to subcutaneous treprostinil on post-operative day 3 , and she was discharged on post-operative day 13 .

She was followed closely in our multidisciplinary pulmonary hypertension outpatient clinic and is now 18 months post-transplant. Management of her pulmonary hypertension therapy was based on clinical symptoms and objective measurements such as echocardiography, 6MW, and spirometry. At her first outpatient visit 3 weeks posttransplant, she had no significant clinical symptoms and a predicted right ventricular pressure that was $1 / 3$ her systemic pressure based on TR jet velocity, so a 5 -week wean of her treprostinil was initiated and completed without worsening clinical symptoms or pulmonary hypertension as assessed by echocardiogram. 6MW test remained improved from baseline at the first clinic visit off of treprostinil, with a distance of $487 \mathrm{~m}$. Over the next several months, she showed a steady improvement in right ventricular size, function, and pressure along with a sustained improvement in clinical symptoms and improvement in spirometry with an FEV1 $\sim 85 \%$. By 6 months post-transplant, she had returned to half days at school and successfully weaned off her Macitentan. At 16 months post-transplant, her echocardiogram showed normal right ventricular size, function, and pressure and she tolerated discontinuation of her tadalafil.

\section{DISCUSSION}

Portopulmonary hypertension occurs independent of the cause of portal hypertension and does not seem to correlate with the severity of liver disease. It is categorized as mild, moderate, or severe based on the pulmonary artery pressure measurements.11, 12 The mechanism of PPHTN development is multifactorial and likely related to endotoxins and cytokines released secondary to overload of the splanchnic vasculature. These mediators bypass the liver and have direct effects on the pulmonary vasculature, including pulmonary vasoconstriction. It is also theorized that endotoxins lead to pulmonary vasodilation, which when coupled with the sheer stress associated with the high cardiac output state of liver failure, causes endothelial damage and pulmonary vascular remodeling. 
Due to the subtle clinical presentation of PPHTN, patients often have moderate-to-severe disease at the time of diagnosis, precluding them from liver transplant. Current guidelines recommend liver transplantation in patients with a mean pulmonary artery pressure $<35 \mathrm{~mm} \mathrm{Hg}$ or in patients with a mean PAP between 35 and $50 \mathrm{~mm} \mathrm{Hg}$ with a PVR of $<3$ wood units. 13

While PPHTN is not a sole indication for liver transplantation in adults, 1 the 2014 Practice Guidelines for pediatric liver transplantation recommend that children with the evidence of PPTHN be promptly referred for liver transplant evaluation and that listed patients with severe PPHTN who are responsive to medical therapy qualify for a model for end-stage liver disease score exception to receive a liver transplant.14 Our hepatology service felt that the severity of her PPHTN and degree of liver failure warranted proceeding with listing for liver transplantation.

Reports of PPHTN and treatment in the pediatric population are limited. The multi-center PPHTN database published in 2004 did not include any children. Losay et al $\underline{\mathbf{1 5}}$ published their experience with liver transplant in three children who did not receive pre-operative

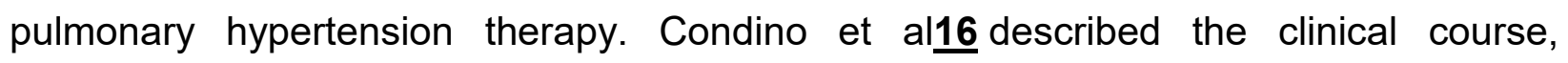
evaluation, and management of seven pediatric patients with severe PPHTN, four of whom died and none of whom were eligible for liver transplant despite medical therapy. To date, the only successful liver transplant reported in a pediatric patient with severe PPHTN was accomplished after four months of intravenous epoprostenol.11

Our patient had severe PPHTN with mild reduction in MPAP and PVR with the administration of $100 \%$ oxygen and iNO. Although our patient's chest $X$-ray was grossly abnormal, echocardiography remains the best screening tool for PPHTN.17 This report underscores the importance of periodic screening in this patient population. By using a combination of enteral and parenteral therapies, each targeting different pathways that lead to pulmonary vasodilation, we were able to successfully lower our patient's pulmonary artery pressure from severe to a level acceptable for liver transplantation after 2 months of treatment. Further, we were able to interchange subcutaneous therapy with intravenous therapy to avoid problems with subcutaneous absorption that may have been associated with significant fluid shifts in the post-operative state. Significant side effects 
associated with treprostinil initiation necessitated slow titration. In the face of her underlying liver disease and the fact that treprostinil is largely metabolized by the liver, a slower increase in this medicine may have minimized the amount of side effects that she experienced. Eventually, her aminotransferase and total and direct bilirubin levels improved with treatment, and she tolerated initiation of an endothelin receptor antagonist without detrimental hepatotoxicity. Although some have proposed that a mutation in the bone morphogenetic protein receptor type 2 may be a key factor in idiopathic pulmonary hypertension, $1 \mathbf{1 8}$ our patient was negative for mutations in this gene and it has never been implicated in PPHTN.

Lastly, while our patient demonstrated sustained improvement in her PPHTN and proved able to come off all of her therapy, we heed caution when considering aggressively weaning therapy in the first several months post-transplant. While liver transplantation can reverse portal hypertension, the remodeling of the vasculature that results in pulmonary hypertension can sometimes prove to be irreversible.19 Clinicians should base their weaning schedule on patient symptoms and objective data such as echocardiogram, 6MW, PFTs, and catheterization-based hemodynamics, when needed.

This report adds to the sparse data on successful use of pulmonary vasodilator therapy as a means to improve right-sided hemodynamics prior to liver transplant in pediatric patients with severe PPHTN. It is the first report that describes the successful use of early combination therapy to treat severe PPHTN as a bridge to successful liver transplantation. The optimum strategy appears to be early identification and aggressive monitoring with therapies as indicated in order to avoid the development of irreversible pulmonary vasculopathy. Our report demonstrates that, even if PPHTN is severe, aggressive triple therapy can be administered safely, quickly, and may allow for successful liver transplantation.

\section{AUTHOR CONTRIBUTIONS}

All authors have contributed to the drafting, editing, and approval of the final draft.

\section{REFERENCES}


1.Kuo, P. C., Plotkin, J. S., Gaine, S., Schroeder, R. A., Rustgi, V. K., Rubin, L. J., \& Johnson, L. B. (1999). PORTOPULMONARY HYPERTENSION AND THE LIVER TRANSPLANT CANDIDATE. Transplantation, 67(8), 1087-1093.

2.Swanson, K. L., Wiesner, R. H., Nyberg, S. L., Rosen, C. B., \& Krowka, M. J. (2008). Survival in Portopulmonary Hypertension: Mayo Clinic Experience Categorized by Treatment Subgroups. American Journal of Transplantation, 8(11), 2445-2453. https://doi.org/10.1111/j.1600-6143.2008.02384.x

3.Sithamparanathan, S., Nair, A., Thirugnanasothy, L., Coghlan, J. G., Condliffe, R., Dimopoulos, K., Elliot, C. A., Fisher, A. J., Gaine, S., Gibbs, J. S. R., Gatzoulis, M. A., E. Handler, C., Howard, L. S., Johnson, M., Kiely, D. G., Lordan, J. L., Peacock, A. J., PepkeZaba, J., Schreiber, B. E., ... Corris, P. A. (2017). Survival in portopulmonary hypertension: Outcomes of the United Kingdom National Pulmonary Arterial Hypertension Registry. The Journal of Heart and Lung Transplantation, 36(7), 770-779. https://doi.org/10.1016/j.healun.2016.12.014

4.Krowka, M. J., Miller, D. P., Barst, R. J., Taichman, D., Dweik, R. A., Badesch, D. B., \& McGoon, M. D. (2012). Portopulmonary Hypertension: A Report From the US-Based REVEAL Registry. Chest, 141(4), 906-915. https://doi.org/10.1378/chest.11-0160

5.Krowka, M. J., Frantz, R. P., McGoon, M. D., Severson, C., Plevak, D. J., \& Wiesner, R. H. (1999). Improvement in pulmonary hemodynamics during intravenous epoprostenol (prostacyclin): A study of 15 patients with moderate to severe portopulmonary hypertension. Hepatology, 30(3), 641-648. https://doi.org/10.1002/hep.510300307

6.Khaderi, S., Khan, R., Safdar, Z., Stribling, R., Vierling, J. M., Goss, J. A., \& Sussman, N. L. (2014). Long-term follow-up of portopulmonary hypertension patients after liver transplantation. Liver Transplantation, 20(6), 724-727. https://doi.org/10.1002/lt.23870

7.Sussman, N., Kaza, V., Barshes, N., Stribling, R., Goss, J., O’Mahony, C., Zhang, E., Vierling, J., \& Frost, A. (2006). Successful Liver Transplantation Following Medical Management of Portopulmonary Hypertension: A Single-Center Series. American Journal of Transplantation, 6(9), 2177-2182. https://doi.org/10.1111/j.1600-6143.2006.01432.x

8.Hollatz, T. J., Musat, A., Westphal, S., Decker, C., D'Alessandro, A. M., Keevil, J., Zhanhai, L., \& Runo, J. R. (2012). Treatment with sildenafil and treprostinil allows 
successful liver transplantation of patients with moderate to severe portopulmonary hypertension. Liver Transplantation, 18(6), 686-695. https://doi.org/10.1002/lt.23407

9.Sakai, T., Planinsic, R. M., Mathier, M. A., Vera, M. E. de, \& Venkataramanan, R. (2009). Initial experience using continuous intravenous treprostinil to manage pulmonary arterial hypertension in patients with end-stage liver disease. Transplant International, 22(5), 554-561. https://doi.org/10.1111/j.1432-2277.2008.00830.x

10. Laving, A., Khanna, A., Rubin, L., Ing, F., Dohil, R., \& Lavine, J. E. (2005). Successful Liver Transplantation in a Child with Severe Portopulmonary Hypertension Treated with Epoprostenol. Journal of Pediatric Gastroenterology and Nutrition, 41(4), 466-468. https://doi.org/10.1097/01.mpg.0000178441.10417.0f

11. Rodríguez-Roisin, R., Krowka, M. J., Hervé, P., \& Fallon, M. B. (2004). PulmonaryHepatic vascular Disorders (PHD). European Respiratory Journal, 24(5), 861-880. https://doi.org/10.1183/09031936.04.00010904

12. Krowka, M. J., Plevak, D. J., Findlay, J. Y., Rosen, C. B., Wiesner, R. H., \& Krom, R. A. F. (2000). Pulmonary hemodynamics and perioperative cardiopulmonary-related mortality in patients with portopulmonary hypertension undergoing liver transplantation. Liver Transplantation, 6(4), 443-450. https://doi.org/10.1053/jlts.2000.6356

13. Squires, R. H., Ng, V., Romero, R., Ekong, U., Hardikar, W., Emre, S., \& Mazariegos, G. V. (2014). Evaluation of the Pediatric Patient for Liver Transplantation: 2014 Practice Guideline by the American Association for the Study of Liver Diseases, American Society of Transplantation and the North American Society for Pediatric Gastroenterology, Hepatology, and Nutrition. Journal of Pediatric Gastroenterology and Nutrition, 59(1), 112-131. https://doi.org/10.1097/MPG.0000000000000431

14. Losay, J., Piot, D., Bougaran, J., Ozier, Y., Devictor, D., Houssin, D., \& Bernard, O. (1998). Early liver transplantation is crucial in children with liver disease and pulmonary artery hypertension. Journal of Hepatology, 28(2), 337-342. https://doi.org/10.1016/0168-8278(88)80022-9

15. Condino, A. A., Ivy, D. D., O'Connor, J. A., Narkewicz, M. R., Mengshol, S., Whitworth, J. R., Claussen, L., Doran, A., \& Sokol, R. J. (2005). Portopulmonary Hypertension in Pediatric Patients. The Journal of Pediatrics, 147(1), 20-26. https://doi.org/10.1016/j.jpeds.2005.02.019 
16. Colle, I. O., Moreau, R., Godinho, E., Belghiti, J., Ettori, F., Cohen-Solal, A., Mal, H., Bernuau, J., Marty, J., Lebrec, D., Valla, D., \& Durand, F. (2003). Diagnosis of portopulmonary hypertension in candidates for liver transplantation: A prospective study. Hepatology, 37(2), 401-409. https://doi.org/10.1053/jhep.2003.50060

17. Morrell, N. W. (2006). Pulmonary Hypertension Due to BMPR2 Mutation. Proceedings of the American Thoracic Society, 3(8), 680-686. https://doi.org/10.1513/pats.200605-118SF

18. Khaderi, S., Khan, R., Safdar, Z., Stribling, R., Vierling, J. M., Goss, J. A., \& Sussman, N. L. (2014). Long-term follow-up of portopulmonary hypertension patients after liver transplantation. Liver Transplantation 20(6), 724-727. https://doi.org/10.1002/lt.23870 